\title{
A setup for electrically controlled liquid-phase sorption of organic pollutants on nanostructured materials
}

\author{
Elena Neskoromnaya ${ }^{1, *}$, Alexander Babkin ${ }^{1}$, and Alexander Burakov ${ }^{1}$ \\ ${ }^{1}$ Tambov State Technical University, Department “Technology and Methods of Nanoproducts Manufacturing”, 392000, \\ 106 Sovetskaya Str., Tambov, Russia
}

\begin{abstract}
The present paper considers the possibility of intensifying the process of liquid-phase sorption of organic molecules of methyl orange dye through exposure to an electromagnetic field. A laboratory setup for water conditioning and an experimental procedure are presented. Activated carbons of different chemical nature (stone carbon - AG-5, charcoal - BAU-A, and NWC coconut shell carbon in its initial form - NWC and nanomodified with carbon nanotubes - NWC-T) were used as sorption materials. Moreover, the possibility of employing "Taunit"-series (Taunit, Taunit-M, Tainit-MD) carbon nanotubes (CNTs), produced at NanoTechCenter Ltd. (Tambov, Russia), in its native form in the process of electrically controlled sorption was also evaluated. In the course of performing comparative studies, the positive influence of the electromagnetic field on the sorption process was established. The adsorption capacity of the sorbents was found to increase 1.5-2 times under the voltage of $100 \mathrm{~V}$. The sorption activity of the materials under study increased in the following sequence: $\mathrm{BAU}-\mathrm{A}<\mathrm{AG}-5<\mathrm{NWC}<\mathrm{NWC}-\mathrm{T}$ $<$ "Taunt"<"Taunit-MD"<"Taunit-M".
\end{abstract}

\section{Introduction}

Electrical sorption taking place in a heterogeneous medium under the influence of an external electric field is one of the varieties of sorption technologies. An electric water conditioner represents a water purification system comprising a filter element with porous adsorbents and electrodes that generate an electromagnetic field. This device can be used for treating wastewater to remove dangerous pollutants of different chemical nature $[1,2]$.

In the present work, the possibility of improving the qualitative characteristics of liquid-phase sorption from aqueous media due to directed electromagnetic exposure in the presence of highly effective sorbents - industrial activated carbons (ACs) and other types of carbon materials - carbon nanotubes (CNTs) - was studied.

Electrochemical polarization of the carbon surface shifts the adsorption equilibrium and, consequently, can be a regulating factor in adsorption systems. The influence of an external electric field on the sorbent causes the polarization of its granules, thereby substantially increasing the electrical sorption of ionmolecular aggregates of the pollutant from an aqueous solution. In adsorption processes involving carbon materials, a change in electric potential occurs at the interface, which appears to be the most pronounced in the case of aqueous solutions. Thus, the controlled electromagnetic influence should contribute to an increase in the sorption activity of the particle $[1,2]$.
The main groups of physical and physical-chemical factors essential for the electrical sorption are as follows:

$\checkmark$ the distribution of the electric field takes place in a sorption cell with a porous material;

$\checkmark$ the process implies interaction of chemical substances with each other and with water, as well as with adsorbing materials, in the external electric field;

$\checkmark$ the relationship is established between molecules and electrical charges of impurities present in the aqueous solution, in near-electrode zones and directly on the electrodes.

The specific surface area of the ACs is very high and equals to $1 \cdot 10^{5}-2 \cdot 10^{5} \mathrm{~m}^{2} / \mathrm{kg}$, and their bulk density is $200-900 \mathrm{~kg} / \mathrm{m}^{3}$. A large number of functional groups have been found on the AC surface: phenol, carbonyl, carboxyl, ester, enol, and lactone. The heteroatoms nitrogen and sulfur - are often included in six-membered rings. These features of the surface of the ACs frequently determine their ion-exchange and catalytic activity [3, 4].

Since the issue regarding the quality of water consumed is acute during the past years, it is important to develop novel materials capable of extracting different types of pollutants to maximum permissible values, or modify the already existing most widely used adsorbents. At present, many works have aimed at studying standard samples of adsorbing materials and the ability of their surface for activation or modification to improve the key adsorption characteristics.

In the present work CNTs under trade mark "Taunit" three different types (Taunit, Taunit-M, Tainit-

*Corresponding author: lenok.n1992@mail.ru 
MD) (Table 1), produced at NanoTechCenter Ltd. (Tambov, Russia), were used as a compared material in the adsorption.

CNTs possess a high specific surface area (for single-walled CNTs - up to $3,000 \mathrm{~m}^{2} / \mathrm{g}$ ) and reactivity. Therefore, adsorption processes are one of the promising trends in their use [5-7].

Table 1. Characteristics of the "Taunit"-series CNTs.

\begin{tabular}{|c|c|c|c|}
\hline Parameter & "Taunit" & "Taunit-M" & $\begin{array}{c}\text { "Taunit- } \\
\text { MD" }\end{array}$ \\
\hline $\begin{array}{c}\text { Outer diameter, } \\
\mathrm{nm}\end{array}$ & $20-70$ & $8-15$ & $30-80$ \\
\hline $\begin{array}{c}\text { Inner diameter, } \\
\mathrm{nm}\end{array}$ & $5-10$ & $4-8$ & $10-20$ \\
\hline Length, $\mu \mathrm{m}$ & 2 and more & 2 and more & 20 and more \\
\hline $\begin{array}{c}\text { Bulk density, } \\
\mathrm{g} / \mathrm{cm}^{3}\end{array}$ & $0.4 \div 0.6$ & $0.03 \div 0.05$ & $0.03 \div 0.05$ \\
\hline $\begin{array}{c}\text { Specific } \\
\text { geometric } \\
\text { surface area, } \\
\mathrm{m}^{2} / \mathrm{g}\end{array}$ & $\begin{array}{c}120 \text { and } \\
\text { more }\end{array}$ & $180-200$ & $\begin{array}{c}300 \text { and } \\
\text { more }\end{array}$ \\
\hline $\begin{array}{c}\text { Adsorption } \\
\text { activity } \\
\text { regarding } \\
\text { methylene blue, } \\
\mathrm{mg} / \mathrm{g}^{*}\end{array}$ & 110.0 & 207.5 & 275.0 \\
\hline $\begin{array}{c}\text { Thermal stability } \\
\left({ }^{\circ} \mathrm{C}\right)\end{array}$ & up to 600 & up to 600 & up to 600 \\
\hline
\end{tabular}

Thus, in the present study, all three abovedescribed CNTs types were used for electrically controlled liquid-phase sorption, together with the starting (initial) and nanomodified ACs.

\section{Experimental}

\subsection{A Laboratory Setup}

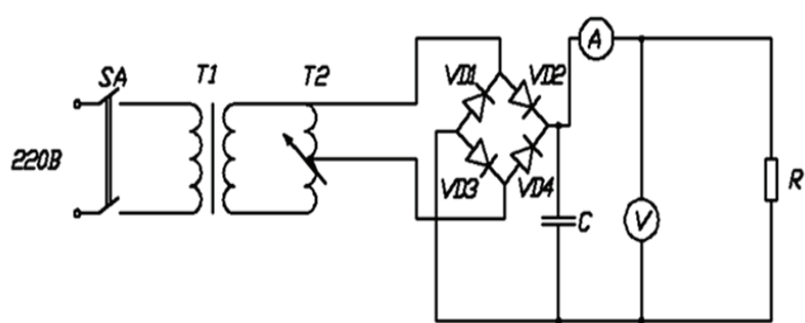

Fig. 1. A schematic diagram of the laboratory setup for electric water conditioning.

The authors have developed a setup for the implementation of the sorption process under the influence of an electromagnetic field. The electric water conditioner represents a closed circuit for circulation of an aqueous solution. The main element is a sorption cell with a sample of the adsorbing material and electrodes for generating an electrostatic field.

The schematic diagram of the laboratory setup is shown in Fig. 1, and its exterior is given in Fig. 2.

The voltage $(220 \mathrm{~V})$ is applied to the isolation transformer T1 via the two-pole circuit breaker SA protected against restart and short circuit.

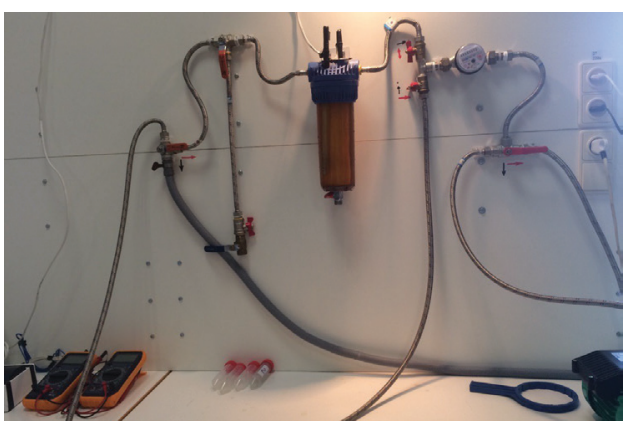

Fig. 2. The laboratory setup for studying the influence of the electromagnetic field on sorption processes.

Since water is an ionic conductor, the transformer is a necessary element in the setup to conduct safe research. Next, from the T1, the voltage is routed to the autotransformer $\mathrm{T} 2$ to vary the voltage in the range of 0 $220 \mathrm{~V}$.

\subsection{Materials}

After analyzing a large number of studies in the field of creating new adsorbents and methods for modifying standard sorption materials, the authors of the present paper have developed a technology for obtaining nanomodified sorbents. The sorbent proposed herein was synthesis via a CVD method in the course of growing carbon nanotubes over the surface of coconut shell AC [8].

Electron images (Fig. 3) of nanomodified ACs were obtained by scanning electron microscopy (SEM) on a Neon 40 two-beam instrument (Carl Zeiss, Jena, Germany).

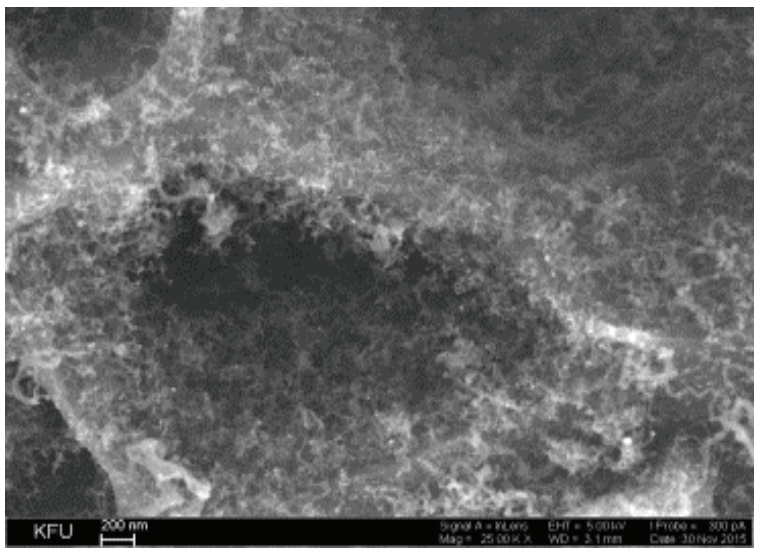

Fig. 3. A micrograph of the surface of the coconut shell carbon modified with a CNTs layer.

Different ACs (BAU-A charcoal, AG-5 stone carbon, and NWC coconut shell carbon) and "Taunit"-series CNTs were used as reference materials. The structure of some of them is presented in Fig. 4.

All the AC-based sorption materials were subjected to preliminary treatment and drying for $2 \mathrm{~h}$ at a temperature of $120-150{ }^{\circ} \mathrm{C}$. 


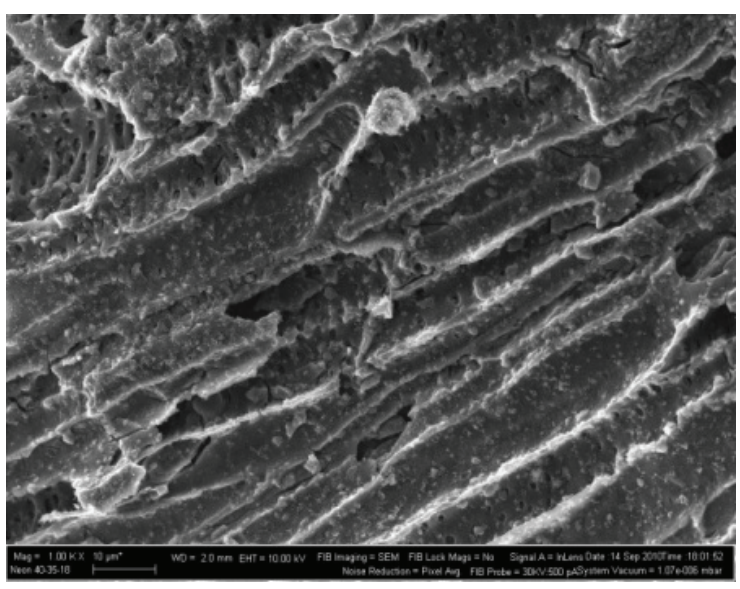

(a)

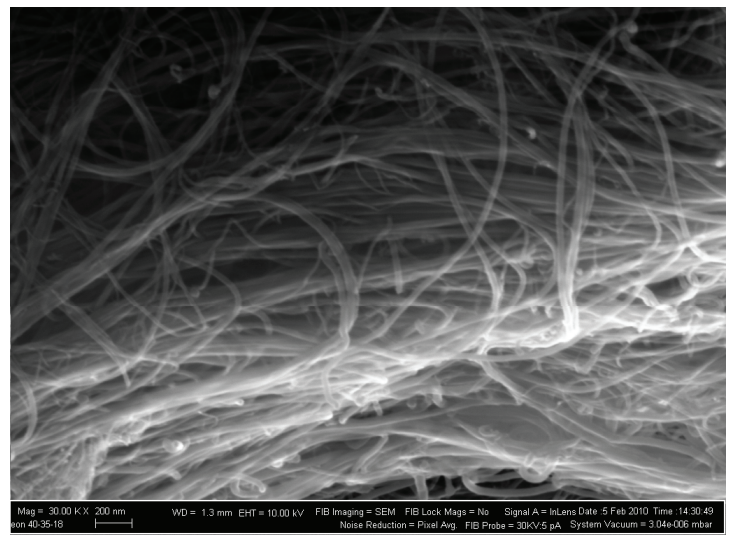

(b)

Fig. 4. The structure of the NWC AC (a) and "Taunit-M" CNTs (b).

The widely known artificial dye - methyl orange (MO) [other names: helianthin, benzenesulfonate, and sodium p-dimethylaminoazobenzenesulfonate] - was used as model organic pollutant. Its formula is given in Fig. 5.<smiles>CN(C)c1ccc(/N=N/c2ccc(S(=O)(=O)[O-])cc2)cc1</smiles>

Fig. 5. The chemical formula of methyl orange.

This substance is a sodium salt and represents an acid-base indicator. In addition to the main field of its application as indicator, it is also used in the textile industry for dyeing wool, silk and nylon due to its chemical properties.

\subsection{Adsorption studies}

To determine the quantitative parameters of the adsorption process, the standard method of spectrophotometric analysis, described in the Russian National Standard (GOST) No. 4453-74 [9], was implemented.
Concentration values of solutions were calculated through optical densities and were obtained spectrophotometrically on a PE $5400 \mathrm{~V}$ instrument (Ekros Ltd., St. Petersburg, Russia) at a wavelength of $400 \mathrm{~nm}$. At the preparatory stage of the experiment, a calibration graph was constructed.

A $1500 \mathrm{mg} / \mathrm{L}$ stock (initial) solution was prepared by dissolving $1.5 \mathrm{~g}$ of the $\mathrm{MO}$ in $1 \mathrm{~L}$ of distilled water and standing for several hours. From this solution, the samples containing the MO concentrations of 30,60 , 120, 180 and $240 \mathrm{mg} / \mathrm{L}$ were obtained using the corresponding dissolutions. The optical density of each sample was measured on the spectrophotometer. Distilled water was used as reference sample. Each sample was replicated 3 times to achieve values with the least error.

To evaluate the effect of the electric field on the adsorption, the experiments were performed on the setup shown in Figs. 1 and 2. The stock solution (volume 4 L) having an initial concentration of $150 \mathrm{mg} / \mathrm{L}$ was supplied from the reservoir (using a centrifugal pump) into a sorption flask containing a filter element with the adsorbent and also two electrodes, to which the voltage of $0-150 \mathrm{~V}$ was applied. From the sorption flask, the solution was returned to the original reservoir through the reverse loop. The solution flow rate was controlled using a SV-15G meter (Meter, Moscow, Russia). The adsorbent mass was 20 (in the case of the ACs) 2 (in the case of the CNTs) g.

The adsorption capacity of the adsorbent materials was estimated according to the following equation:

$$
Q_{e}=\left(C_{0}-C_{e}\right) \cdot V / m
$$

where $\mathrm{V}$ is the sample volume $(\mathrm{L}), \mathrm{m}$ is the adsorbent mass $(\mathrm{g}), \mathrm{C}_{\mathrm{o}}$ is the MO initial concentration $(\mathrm{mg} / \mathrm{L})$, and $\mathrm{C}_{\mathrm{e}}$ is the $\mathrm{MO}$ equilibrium concentration in the solution $(\mathrm{mg} / \mathrm{L})$.

High adsorption values can be obtained by using the NWC carbon and "Taunit-M" CNTs. To confirm this fact, experiments were carried out on the laboratory setup without use of the electric field. The experimental results obtained are presented in Figs. 6 and 7.

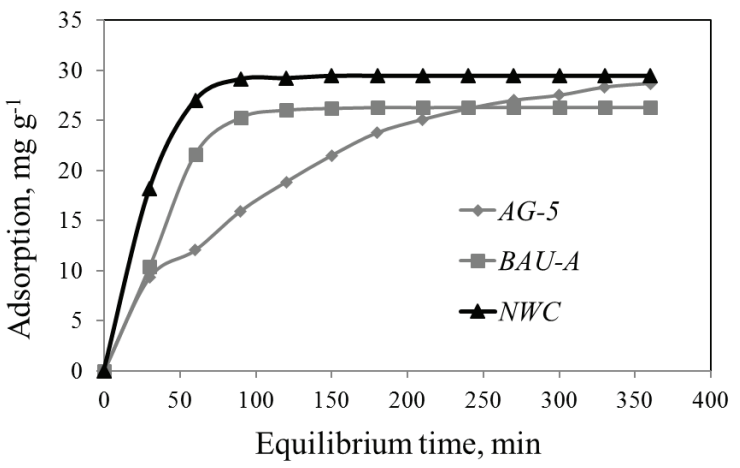

Fig. 6. Kinetic curves constructed for the $\mathrm{MO}$ adsorption from aqueous solutions on the ACs: NWC, AG-5, and BAU-A (under normal conditions). 


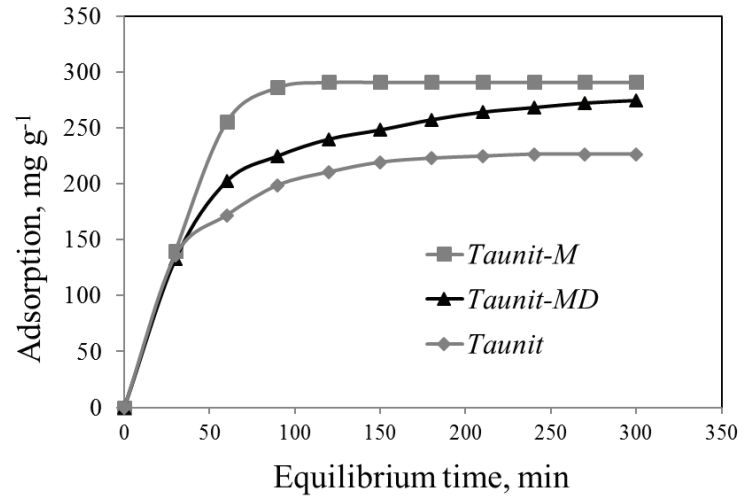

Fig. 7. Kinetic curves constructed for the MO adsorption from aqueous solutions on the CNTs: "Taunit", "Taunit-M", and "Taunit-MD" (under normal conditions).

The analysis of these shows that each adsorbent under study has its own kinetic features of the organic dye sorption, and the NWC AC and the "Taunit-M" CNTs possess the maximum sorption activity (Table 2).

Table 2. Adsorption capacity of the carbon materials under study.

\begin{tabular}{|c|c|c|}
\hline Material & $\begin{array}{c}\text { Adsorption } \\
\text { capacity, mg/g }\end{array}$ & $\begin{array}{c}\text { Equilibrium } \\
\text { time, min }\end{array}$ \\
\hline \multicolumn{3}{|c|}{ Activated carbons } \\
\hline NWC & $\mathbf{2 9}$ & $\mathbf{9 0}$ \\
\hline AG-5 & 27 & 360 \\
\hline BAU-A & 26 & 120 \\
\hline \multicolumn{3}{|c|}{ Carbon nanotubes } \\
\hline Taunit & 210 & 170 \\
\hline Taunit-M & $\mathbf{2 8 0}$ & $\mathbf{1 1 0}$ \\
\hline Taunit-MD & 260 & 300 \\
\hline
\end{tabular}

Thus, for further studies of the electric field effect, it is advisable to employ the two most sorptionally active materials - NWC AC and "Taunit-M" CNTs.

The effect of the influence of the electromagnetic field on the sorption process on the CNTs (Fig. 8) and the ACs (Fig. 9) was studied at fixed voltage values (0$150 \mathrm{~V})$ in $50 \mathrm{~V}$ increments. Samples for diagnosis were taken at 20 min intervals.

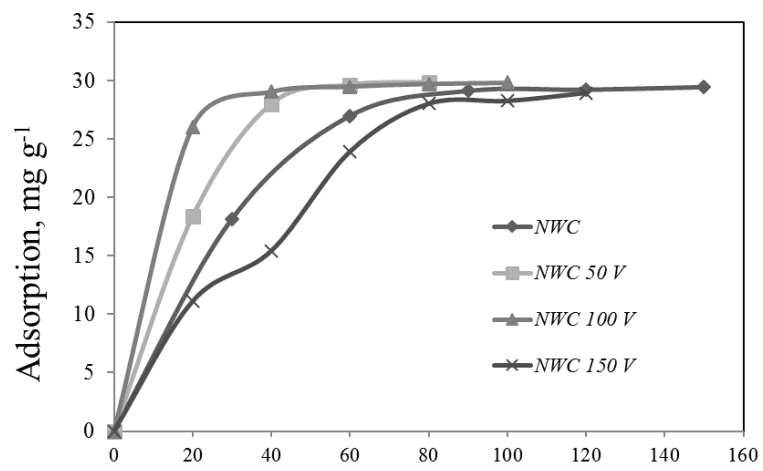

Equilibrium time, min

Fig. 8. Kinetic curves constructed for the MO adsorption from aqueous solutions on the initial NWC AC under the voltages of 50,100 and $150 \mathrm{~V}$.

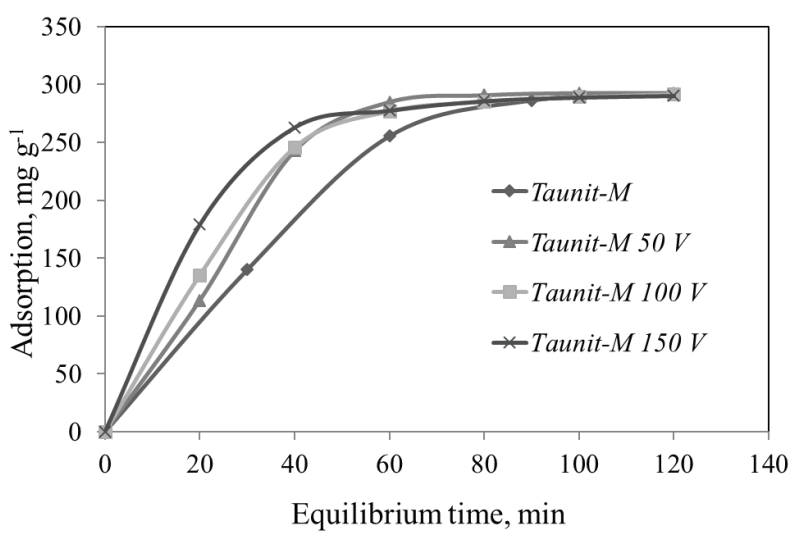

Fig. 9. Kinetic curves constructed for the MO adsorption from aqueous solutions on the "Taunit-M" CNTs under the voltages of 50,100 and $150 \mathrm{~V}$.

Analyzing the graphs constructed for the "Taunit-M" CNTs, it can be concluded about the opposite results with respect to the standard $\mathrm{AC}$. The equilibrium time for the pollutant recovery process is reached under the influence of the electric field with a voltage of $100 \mathrm{~V}$, which is 1.5 times faster than in the absence of voltage.

The results of the studies on the adsorption characteristics of the nanomodified samples using the electromagnetic field are presented in Fig. 10.

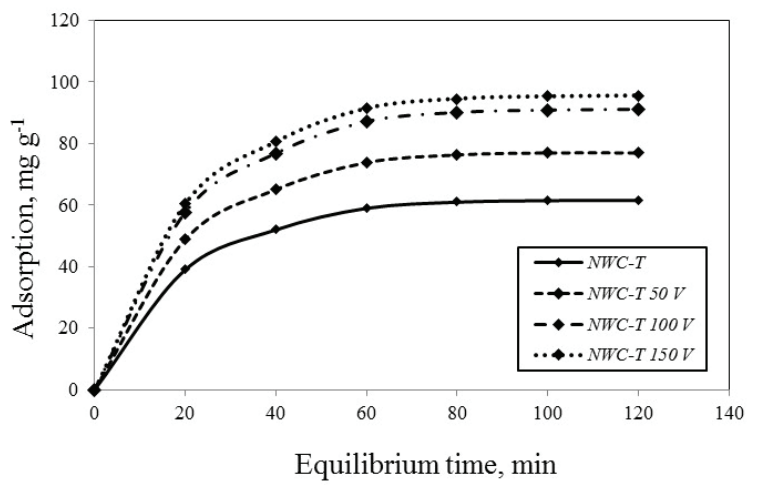

Fig. 10. Kinetic curves constructed for the $\mathrm{MO}$ adsorption from aqueous solutions on the NWC-T AC under the voltages of 50,100 and $150 \mathrm{~V}$.

From this figure, it can be seen that at the same equilibrium time for all the nanomodified AC samples, the maximum adsorption capacity $(90 \mathrm{mg} / \mathrm{g})$ corresponds to the voltage of $100 \mathrm{~V}$.

Thus, as a result of the experimental studies, the comparative data shown in Table 3 were obtained.

Table 3. Adsorption capacity of the sorbents under the influence of electromagnetic field.

\begin{tabular}{|c|c|c|c|c|c|c|}
\hline & \multicolumn{2}{|c|}{ NWC } & \multicolumn{2}{|c|}{$\begin{array}{l}\text { "Taunit-M" } \\
\text { CNTs }\end{array}$} & \multicolumn{2}{|c|}{ NWC-T } \\
\hline Voltage, $\mathrm{V}$ & $\begin{array}{l}\mathrm{Q}_{\mathrm{e}} \\
\mathrm{mg} / \mathrm{g}\end{array}$ & $\begin{array}{l}\text { Time } \\
\text { min }\end{array}$ & $\begin{array}{c}\mathrm{Q} \text { e, } \\
\mathrm{mg} / \mathrm{g}\end{array}$ & $\begin{array}{l}\text { Time } \\
\text { min }\end{array}$ & $\begin{array}{l}\mathrm{Qe} \\
\mathrm{mg} / \mathrm{g}\end{array}$ & $\begin{array}{c}\text { Time, } \\
\text { min }\end{array}$ \\
\hline 0 & 29 & 90 & 280 & 110 & 60 & \\
\hline 50 & 29 & 60 & 280 & 80 & 73 & \\
\hline 100 & 29 & 37 & 285 & 80 & 90 & 80 \\
\hline 150 & 28 & 120 & 275 & 100 & 92 & \\
\hline
\end{tabular}


Analyzing the results presented in Table 3, it can be clearly seen that the optimum voltage is $100 \mathrm{~V}$ for all the samples. Under these conditions, the maximum adsorption capacity is achieved in a shorter period of time. The activity of the sorption materials can be distributed in the following sequence: BAU-A $<$ AG$5<$ NWC $<$ NWC-T $<$ "Taunt" $<$ "Taunit-MD" $<$ "Taunit-M".

\section{Conclusions}

The authors of this works have proved that the electric field really intensifies the process of extracting the organic pollutant molecules from aqueous solutions. The studies aimed at carrying out a number of experiments using a special laboratory facility. The influence of the electric field of different strength was elucidated and the degree of the influence of this external factor on the key sorption characteristics of the carbon materials was calculated based on the results obtained.

It was found that the voltage superposition increases the adsorption capacity of the sorbents (ACs, CNTs) while reducing the process time. The sorption activity of the materials under study lies in the following sequence: BAU-A $<$ AG-5 < NWC $<$ NWC-T $<$ "Taunt" < "TaunitMD" < "Taunit-M".

Thus, the research carried out allows for drawing a conclusion about the positive influence of the electrostatic exposure on the sorption activity of the adsorbents during the extraction of organic pollutants from aqueous media, thereby contributing to the prospects of using the method of electrically controlled sorption on carbon materials on an industrial scale.

The research was funded by the Ministry of Education and Science of the Russian Federation (Project No. 16.1384.2017/PCh).

\section{References}

1. M.A. Tsvetnov, Adsorption and electrical sorption of mono- and semi-functional organic compounds from aqueous and aqueous-organic media on granular and fibrous carbon materials (PhD (Candidate of Chemical Sciences) Thesis, Vladivostok, 2002)

2. N.I. Gel'perin, Basic processes and devices of chemical technology. Parts 1 and 2 (Chemistry, Moscow, 1981)

3. A. Mohammad-Khah, R. Ansari Int. J. Chem. Tech. Res., 1, 4 (2009)

4. Wu Yunhai, Wen Yajun, Zhou Jianxin, Cao Julin, Jin Yanping, Wu Yunying, Environ. Sci. Pollut. Res., 20, 4 (2013)

5. Xuemei Ren, Changlun Chen, Masaaki Nagatsu, Xiangke Wang, Chem. Eng. J., 170 (2011)

6. T.P. Dyachkova, Yu. A. Khan, N. V. Orlova, S. V. Kondrashov, Vestnik TSTU, 324 (2016)

7. D.V. Tarov, T.V. Gurova, I.N. Shubin, Vestnik TSTU, 361 (2015)

8. A. Burakov, I. Romantsova, A. Kucherova A. Tkachev, Ads. Sci. Tech., 32 (9) (2014)
9. Russian National Standard GOST No. 4453-74 A Powder of Active Clarifying Charcoal. Technical Conditions (1996) 